\title{
Hollywood y el Estado. El apoyo del gobierno americano a su industria cinematográfica durante la dictadura de Primo de Rivera
}

\author{
Rocío DE LA MaYa ReTAMAR \\ Universidad de Málaga (España) \\ rmaya@uma.es
}

\begin{abstract}
Resumen
Aunque cada vez son más los estudios históricos que abordan el éxito de las películas norteamericanas en los mercados extranjeros, se le ha prestado relativamente poca atención a las contribuciones específicas del gobierno de Estados Unidos para alcanzar ese éxito. Este artículo examina el alcance de la asistencia del gobierno norteamericano en relación al mercado cinematográfico español durante esa segunda década del siglo XX, específicamente durante la Dictadura de Primo de Rivera.
\end{abstract}

Palabras clave: Distribución cinematográfica - Estados Unidos - España - Legislación cinematográfica - Intervención gubernamental - Censura cinematográfica

Hollywood and the State. US Government aid in the Spanish film market during the years of Primo de Rivera dictatorship.

\begin{abstract}
As more historical studies addresses the success of American films abroad, still we know little about the specific contributions of US Government in achieving that goal. This article examines the scope of that US Government aid regarding Spanish film market during the second of 20th century, specifically during the years of Primo de Rivera dictatorship.
\end{abstract}

Key Words: Film distribution - United States - Spain - Film Law - State Intervention - Film Censorship

\section{Referencia normalizada:}

De la Maya Retamar. R. (2013) Hollywood y el Estado. El apoyo del gobierno americano a su industria cinematográfica durante la dictadura de Primo de Rivera. Historia y Comunicación Social. Vol. 18 N $^{\circ}$ Especial Noviembre. Págs. 327-339.

Sumario: 1. Introducción. Hollywood y el Estado. 2. Fuentes consultadas. Los archivos de la NARA. 3. La MPPDA y los Departamentos de Estado y Comercio del gobierno de Estados Unidos. 4. Acciones de la embajada americana en Madrid frente a la censura. 4.1 Estereotipos nacionales y la censura. 4.2 El boicot a la Metro y a la First National. 5. Valoración final. 6. Referencias bibliográficas. 7. Notas. 


\section{Introducción. Hollywood y el estado.}

Aunque existe una importante cantidad de estudios históricos que han tratado el éxito de la industria cinematográfica americana en los mercados internacionales, se ha prestado relativamente poca atención a las contribuciones específicas del gobierno de Estados Unidos en la consecución de ese éxito. Las protestas contra la abrumadora presencia de películas americanas en los mercados internacionales comenzaron muy poco después de la Primera Guerra Mundial. El listado de medidas adoptadas por los diferentes gobiernos para frenar la penetración americana nos muestra cómo la distribución internacional cinematográfica también necesita ser considerada en el marco de las políticas estatales.

Posteriormente, en el periodo de entreguerras, el contexto general europeo vivió una mayor participación de los estados en la regulación económica, y esto contribuyó a intervenciones en las políticas de importación cinematográfica, que darían como resultado la implantación de contingentes o cuotas -restricciones cuantitativas sobre la cantidad de importaciones- y aranceles -impuestos gravados sobre las importaciones-, al tiempo que fracasaban los esfuerzos de la naciente producción paneuropea. Autores como Kristin Thompson y Kerry Segrave nos han proporcionado una periodización de las medidas desarrolladas en contra de esta invasión de películas norteamericanas a lo largo de los años 20; Ian Jarvie se ha centrado en las negociaciones políticas que marcaron las relaciones entre los gobiernos canadiense, americano y británico; Trumpbour amplía ese análisis a las relaciones cinematográficas Estados Unidos-Europa, y otros autores como Ulf Jonas Bjork y Ulff-Møller han documentado el activo apoyo del gobierno americano para fomentar la exportación de películas de Hollywood.

Fue durante la década de los años 20 cuando esa cooperación Hollywood-gobierno de Estados Unidos se hizo más importante; tanto el Departamento de Comercio, a través de su Agencia para el Comercio Exterior y Doméstico (Bureau of Foreign and Domestic Commerce), como el Departamento de Estado, prestaron su colaboración a las exportaciones de Hollywood, promoviendo y facilitando su posición en el extranjero. Este artículo pretende arrojar luz sobre el alcance de esa ayuda en el caso específico de España en un contexto históricamente convulso en nuetros país: la dictadura de Primo de Rivera.

\section{Fuentes consultadas. Los archivos de la NARA (National Archives and Records Administration).}

Nuestra investigación se fundamenta en el acceso y análisis de fuentes primarias: los documentos que el gobierno americano conserva en los Archivos Generales de la Administración Federal en Washington. La información aportada por estos materiales es muy valiosa, porque nos permite delimitar las acciones coordinadas que 
gobierno e industria cinematográfica norteamericana llevaron a cabo en el contexto español durante el primer tercio del siglo XX. ${ }^{1}$

Aunque la documentación es muy abundante, los datos recabados podrían clasificarse en torno a tres apartados o asuntos que unifican las acciones emprendidas:

1.- Informes de los cónsules y delegados comerciales de la Embajada estadounidense sobre el mercado cinematográfico español, que abarcaban desde cuestiones generales de España (tamaño del mercado, número de salas, de distribuidores, de productoras, posición del cine americano, etc.) hasta investigaciones más puntuales referidas a una ciudad concreta o a un tipo de actividad;

2.- Acciones contra o para evitar la censura de películas americanas en España;

3.- Y, la más extensa, que aborda las actuaciones del gobierno norteamericano cuando en España se plantea la posibilidad de aprobar medidas legislativas de carácter proteccionista para con la industria cinematográfica nacional.

En este artículo presentaremos algunas de las acciones emprendidas en la segunda línea, aquellas que se llevaron a cabo para sortear la censura española a la distribución de películas norteamericanas en nuestro país.

\section{La MPPDA y los Departamentos de Estado y Comercio del Gobierno de Esta- dos Unidos.}

Al igual que otras industrias, Hollywood ha empleado a lo largo de la historia estrategias para proteger sus productos y sus intereses comerciales tanto en la esfera doméstica como en los mercados internacionales. Estos esfuerzos se concentraron en la creación de una poderosa asociación comercial y en conseguir el apoyo del gobierno federal a la industria.

En 1922 se fundó la Motion Picture Producers and Distributors of America (MPPDA), una asociación comercial creada por las propias majors ${ }^{2}$ con el objetivo de coordinar ciertos aspectos de sus actividades tanto dentro como fuera de los Estados Unidos. Al frente de la misma se nombró a Will H. Hays, que mantenía muy buenas relaciones con el gobierno republicano del entonces Presidente Warren Harding. Tan cercana fue la colaboración con el gobierno norteamericano a través de Hays, que este llegó a ser percibido dentro y fuera de Estados Unidos como un representante gubernamental, lo que le daba acceso a los principales líderes mundiales, y la MPPDA fue bautizada como el "pequeño Departamento de Estado".

Desde su formación, la MPPDA contó con un Comité de Relaciones en el Extranjero, después denominado Departamento Internacional, al frente del cual estuvo Frederick L. Herron desde 1922 a 1941. Su labor fundamental fue la de mantener contactos con las sucursales de sus miembros en el extranjero, con los funcionarios 
a cargo de la importación cinematográfica y con los representantes diplomáticos y el Departamento de Estado en Washington.

Por otra parte, la implicación del gobierno federal en la industria empezó a desarrollarse durante el año fiscal 1912-1913, cuando el Departamento de Comercio introdujo en sus registros de exportación de mercancías los referentes a la exportación cinematográfica. En 1916, el Departamento de Estado dictó órdenes a los cónsules estadounidenses para que elaboraran informes de sus respectivas áreas sobre el mercado para las películas norteamericanas. Algunos de los aspectos requeridos en los informes incluían el número de salas en el área, su tamaño, precios de admisión, nombres de los distribuidores de películas, formas de contratación, etc. Estos informes marcarían el punto de partida de una estrecha cooperación entre el cártel de la industria y el gobierno federal, principalmente a través de los Departamentos de Estado y Comercio, relación que se extendería durante las décadas siguientes. A través de los agregados comerciales y los cónsules de las embajadas se reunió una gran cantidad de documentación que se puso de manera gratuita a disposición de la industria.

A partir de la segunda década del siglo XX, se intensificaron en Europa las reacciones adversas a las películas americanas. Los gobiernos europeos sabían que el éxito arrollador de estas películas estaba dañando la capacidad económica de sus industrias nacionales y, además, "existía el temor de que el influjo de imágenes, temas e historias de América fuera perjudicial para las respectivas culturas nacionales, una preocupación que aumentó el número de quejas sobre el imperialismo americano a través de la "propaganda" cinematográfica" (Bjork, 2000: 4). Varios países de Europa empezaron a instaurar cuotas, aranceles y contingentes para preservar sus mercados domésticos. Hollywood utilizó entonces su influencia política para solicitar la ayuda del gobierno.

\section{Acciones de la embajada americana en Madrid frente a la censura.}

Los documentos gubernamentales norteamericanos recogen abundante documentación sobre las vicisitudes que atravesaron algunas películas americanas en España en diferentes momentos históricos, así como las acciones emprendidas por los miembros de la industria y los representantes políticos del gobierno americano para solventarlas. Nos valdremos de esta información para rastrear las actuaciones censoras que se aplicaron sobre una parte del cine americano que llegó a España.

\subsection{Estereotipos nacionales y censura.}

Cuando a finales de la Primera Guerra Mundial las compañías de Hollywood empezaron a incluir en la contabilidad de sus películas los ingresos procedentes del extranjero como parte de los márgenes de beneficio estimados, "la industria se mostró cada vez más y más atenta a las opiniones de los espectadores de otros países, o bien 
de aquellos que estaban en condiciones de contenerla mediante la censura, la crítica y los boicots" (de Grazia, 2006: 371). Entre las dos guerras mundiales, el 35\% de los ingresos brutos procedían del exterior, y se habían convertido en una parte muy importante de la estructura económica de Hollywood. Los directores de las principales compañías cinematográficas se dieron cuenta de que las ofensas a cualquier parte sustancial del mercado extranjero podía conllevar una pérdida de beneficios por la prohibición o "mutilación" de las películas en esos mercados. Por esa razón, la MPPDA, desde mediados de los años 20, empezó a ajustar los contenidos de sus películas para garantizar que fueran bien recibidas no solo a nivel doméstico, sino también a nivel internacional. Esta forma única de autocontrol terminó concretándose en el Código de Producción que la MPPDA publicó en 1930.

En el mercado interno de Estados Unidos, las representaciones del sexo y del crimen en las películas eran normalmente los asuntos más polémicos y los que concentraban un mayor número de intervenciones censoras por parte de las juntas municipales y estatales. En el extranjero, aunque también se prestaba atención a estos temas, la vigilancia era a menudo más sensible a la representación de denigraciones culturales y estereotipos nacionales: los brutales y cuadriculados alemanes, los ridículos ingleses, los afeminados franceses, los coléricos italianos, los vagos y perezosos hispanos, etc. (Ver ilustración I).

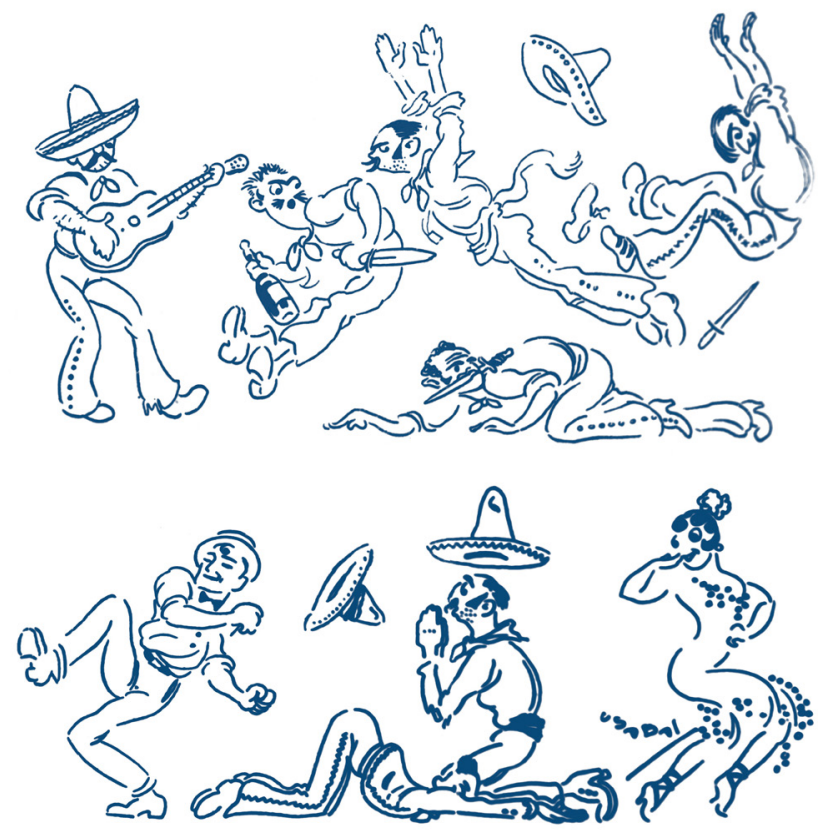

I. Ilustración publicada en la revista Cine-Mundial en el año 1922 a propósito de los estereotipos nacionales representados en las películas americanas. 
En 1926, el cónsul americano en Valencia remitió al Departamento de Estado en Washington el recorte de un artículo publicado en el diario valenciano Las Provincias en el que se ridiculizaban los estereotipos nacionales que se mostraban en las producciones americanas. El cónsul, Clement S. Edwards justificaba el envío apuntando que el suelto daba una idea de "cómo nos ven los demás, y también puede ser de interés para nuestra industria cinematográfica". Un fragmento del artículo decía los siguiente:

Las películas norteamericanas son las más numerosas, las más baratas y las más estúpidas. Son, además, el mejor instrumento para embrutecer a los pueblos. Tienen una moral: la fuerza bruta; una técnica: la vieja técnica de los folletines; un objeto: la propaganda de Estados Unidos, y cuatro personajes: el yanqui, el inglés, el español y el mejicano. Con estos elementos y varios millones de dólares, la cinematografía norteamericana irradia ocho horas diarias sobre cuarenta mil teatros del mundo y estimula la estupidez de media humanidad. [...]Pero las gentes sencillas están aprendiendo con las películas norteamericanas que el español es un ser holgazán, fanfarrón y cobarde; el mejicano, asesino, ladrón y traidor; el inglés, un "dandy" amanerado, elegante y sinvergüenza, y el yanqui, un mozo fuerte, audaz, honrado y valiente. Están aprendiendo también a tener siempre la razón en los puños, a reírse de las finezas del alma, a empañarse los ojos con un sentimentalismo ramplón y a no tener más ideal que el dinero. Como esta enseñanza se da sistemática y divertidamente a las gentes menos aptas para analizarla y rechazarla, ha llegado a ser un evidente peligro para la educación espiritual de los pueblos, aparte de una constante difamación de tres grandes naciones: Inglaterra, España y Méjico. ${ }^{3}$

Poco tiempo después, el agregado comercial de la Embajada de Estados Unidos en Madrid volvía a alertar al Secretario de Estado de que algunas películas americanas estaban recibiendo críticas en España por la representación de los españoles y, por esa razón, eran susceptibles de ser prohibidas en cualquier momento:

[...] Las únicas objeciones que he escuchado contra las películas americanas se basan en las exageraciones que éstas contienen sobre el carácter, la vida y la moral de los españoles. Casi todos los americanos pueden recordar haber visto dos o tres películas en las que el villano siempre se representa como un español dispuesto a apuñalarte por la espalda. Desafortunadamente, para el americano medio que nunca ha viajado, un español es del tipo que cuadra con el villano de la película. ${ }^{4}$

La representación de los españoles y, en general, de los latinos o hispanos en las películas americanas había suscitado una fuerte polémica en los países afectados desde principios de los años 20. El ejemplo más significativo se dio en México, cuyo gobierno estableció un embargo en 1922 sobre toda la producción de las compañías que mostraban, especialmente en las películas del oeste, al mexicano en el papel de malo o villano del film. Según Vasey, el boicot de México sirvió para que los productores americanos se dieran cuenta de las implicaciones de su participación en una distribución a escala global: tenían que considerar el contenido de las películas en relación al alcance previsto de su distribución. En este sentido, Hollywood empezó a mostrar su disposición a realizar concesiones en la representación de los extranjeros en sus películas para no poner en peligro los ingresos procedentes del extranjero (Vasey, 1997: 19). 


\subsection{El boicot a la Metro y a la First National.}

Las compañías de Hollywood no se tomaban a la ligera la pérdida de ningún mercado externo, por pequeño que fuera. Por eso, aunque los ingresos de España representaban aproximadamente solo un $2 \%$ del total procedente del extranjero, cuando en 1927 el gobierno español decretó la prohibición de exhibir las películas Valencia y Lovers? de la Metro-Goldwyn-Mayer en todo el territorio nacional, saltaron las alarmas, sobre todo porque el dictamen no solo afectaba a la proyección, sino que se extendía a las actividades comerciales de la Metro y la First National en España, que quedaron suspendidas. La resolución al conflicto tuvo tres protagonistas principales: el general Primo de Rivera, el embajador norteamericano en España, Ogden H. Hammond ${ }^{5}$, embajador de Estados Unidos en España, y el propio Will H. Hays, presidente de la MPPDA.

La noticia se hizo pública el 17 de octubre de 1927, cuando Ogden H. Hammond remitió un telegrama al Departamento de Estado norteamericano (Ver ilustración II):

Se han prohibido las producciones de la Metro-Goldwyn en España porque la compañía ha exhibido unas películas en Bruselas y Budapest que, según se dice, pueden dañar el prestigio nacional español. Se ha presentado una protesta formal al gobierno, pero de momento no se ha obtenido ningún resultado definitivo. ${ }^{6}$

Las películas a las que se refería el escrito eran Lovers?, dirigida en 1927 por John M. Stahl y protagonizada por Ramón Novarro y Alice Terry, y Valencia, una producción de 1926 del director Dimitri Buchowetzki con Mae Murray y Lloyd Hughes, ambas distribuidas por la Metro-Goldwyn-Mayer. Valencia estaba basada en el famoso pasodoble del compositor José Padilla, que se había convertido en una canción muy popular en Estados Unidos. Lovers?, por su parte, narraba una "escandalosa" historia en la que un hombre joven se enamoraba de la mujer de su tutor legal.

Cuando llegaron noticias al gobierno de Primo de Rivera de que ambas producciones, que se habían exhibido en Bruselas y Budapest, contenían referencias calumniosas a Barcelona, Madrid y España (en el caso de Valencia, por ejemplo, se presentaba al Gobernador de Barcelona, al que se mencionaba como tal en los títulos, como un borracho y derrochador), se dictó una orden que prohibía su proyección en todo el territorio nacional. También se vieron afectadas las actividades comerciales de la Metro-Goldwyn-Mayer y de la First National Pictures en España, que fueron suspendidas temporalmente por expreso mandato del gobierno. La inclusión de First National obedecía a que, en ese momento, la Metro era su distribuidora en España, y las autoridades españolas no distinguieron entre ambas, cuestión que sería subsanada pocos días después. 


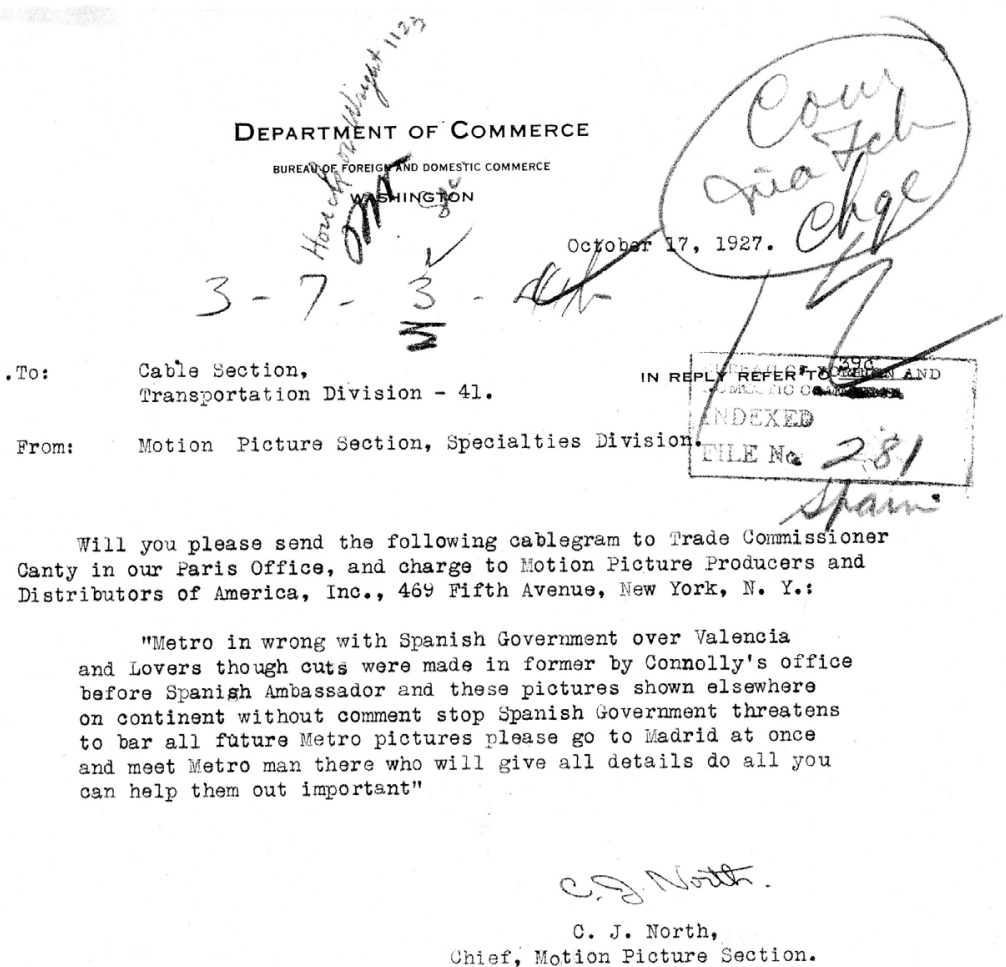

I. Cable del Departamento de Comercio de Estados Unidos anunciando la prohibición de la exhibición de las películas Valencia y Lovers? En España.

William Levis Simpson, gerente de la Metro-Goldwyn-Mayer en España se desplazó hasta Madrid y requirió la intervención del embajador Hammond para solucionar el conflicto. Hammond solicitó una entrevista con el general Primo de Rivera, que le fue concedida el 18 de octubre de 1927. El embajador informó al Secretario de Estado norteamericano del resultado de esa reunión, al tiempo que remitía un escrito a Will Hays para que la MPPDA tomara ciertas medidas sobre el contenido de las películas americanas en el futuro. Reproducimos un amplio fragmento de ese documento porque entendemos que ejemplifican muy bien la labor de los representantes del gobierno norteamericano en esa labor de intermediación entre el gobierno español y los intereses de su propia industria cinematográfica:

[...] Solicité una entrevista con el General Primo de Rivera con el fin de llegar a una solución sobre las quejas españolas y conseguir así que ambas compañías pudieran reanudar sus actividades en España. El General Primo de Rivera retiró inmediatamente la prohibición contra las películas de la First National Corporation, al darse cuenta de la injusticia que suponía embargar sus productos a causa de la exhibición en el extranjero de películas ofensivas de las que no era en ningún modo responsable.

El caso de la Metro-Goldwyn Corporation, sin embargo, fue bastante más difícil, aunque al presente existe la promesa de tratar de llegar a una pronta solución. 
La postura adoptada por el gobierno español para prohibir las películas de esta compañía en España parece inflexible en principio, y solo después de explicarles detenidamente la importancia de la industria cinematográfica en América y la envergadura de los contratos en el extranjero de la Metro-Goldwyn Corporation, el Ministerio de Asuntos Exteriores español ha accedido a contemplar la posibilidad de levantar la prohibición sin la absoluta retirada de las dos películas del mercado internacional.

Tras la llegada a Madrid del Sr. Canty, Agregado Comercial de la Embajada en París, solicité una exhibición privada de las dos películas en cuestión, y me convencí de que no contienen nada esencialmente peyorativo hacia España, y que si se eliminaban ciertas referencias a Madrid, Barcelona y España, se podrían superar las cuestiones objetables.

Trasladé este sentimiento al Subsecretario de Asuntos Exteriores y le manifesté la esperanza de que, ya que la compañía había sufrido una pérdida de 20.000 pesetas en contratos, y en vista del evidente deseo por parte de la misma de cumplir con la petición del gobierno español, las autoridades podían visionar las películas e indicar las partes que considerasen ofensivas, con miras a levantar la prohibición sobre los productos de la compañía tan pronto como fuera posible.

Han accedido a mi solicitud, lo que demuestra la buena voluntad de las autoridades españolas, por lo que albergo la esperanza de que pronto se levante la prohibición.

Sin embargo, el Sr. Almeida, Subsecretario de Asuntos Exteriores, exigió, en nombre del gobierno español, no solo que la compañía eliminase las referencias ofensivas a España, sino que también se comprometiera a no producir películas que contuvieran referencias similares. Es en relación a este asunto por lo que he dirigido una carta al Sr. Hays con fecha 22 de octubre de 1927 de la que le adjunto una copia y el original de la misma para que se la hagan llegar, si así lo aprueba el Departamento.?

En la carta a Will H. Hays, el embajador llamaba la atención hacia las dificultades a las que se habían visto sujetas las compañías cinematográficas americanas y a las que se verían sujetas en el futuro a no ser que se modificara su política en relación a España. Para ello, aconsejaba a la industria de que se abstuvieran de hacer en el futuro "cualquier referencia directa a España o a las ciudades y autoridades españolas en la producción de películas que, aunque están maravillosamente ambientadas, son ficticias y, por tanto, en opinión de las autoridades españolas, pueden ser responsables de causar una suposición errónea de que los rasgos de los personajes representados en ellas son típicos de un país.[...] La belleza y efectividad de las películas no se verá perjudicada por cambiar los títulos y subtítulos para hacer que la acción se ajuste a cualquier país o a ninguno, preferiblemente lo segundo, mediante el empleo de nombres de lugares imaginarios, como ya se ha realizado con éxito en la producción de otras películas como "Graustark", "Zenda", etc."

A principios del mes de noviembre, Hammond informó al Departamento de Estado que, aunque no habían recibido una notificación oficial, "la representación de la embajada en favor de la compañía había sido aparentemente efectiva", ya que la Dirección de Seguridad Pública del gobierno de Primo de Rivera había notificado a los diferentes gobernadores civiles la revocación de la prohibición que pesaba 
sobre las películas de la Metro-Goldwyn-Mayer. Eso sí, la productora tuvo que hacer cambios en Valencia como condición indispensable para que se levantara el embargo que pesaba sobre ella, omitiendo la referencia directa al gobernador de Barcelona. El conflicto, por tanto, se cerraba momentáneamente, aunque el embajador esperaba que se tuvieran en cuenta los consejos que le había dado a Will Hays, de quien aún no había recibido respuesta. Hammond temía por la actitud del gobierno español, que temían sería sin duda mucho más intransigente.

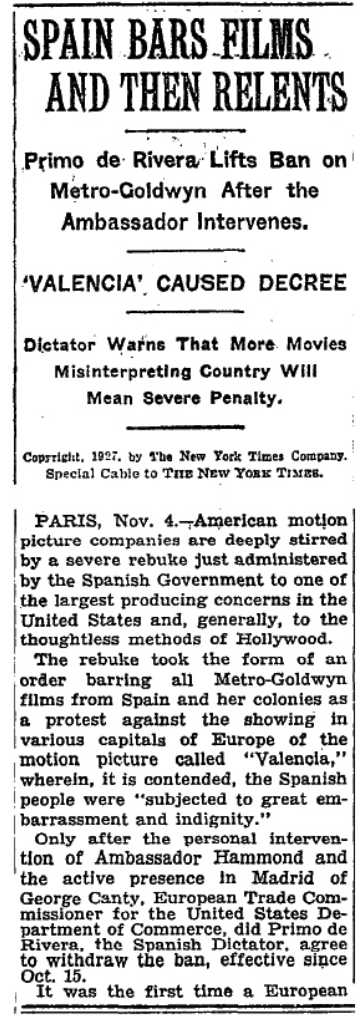

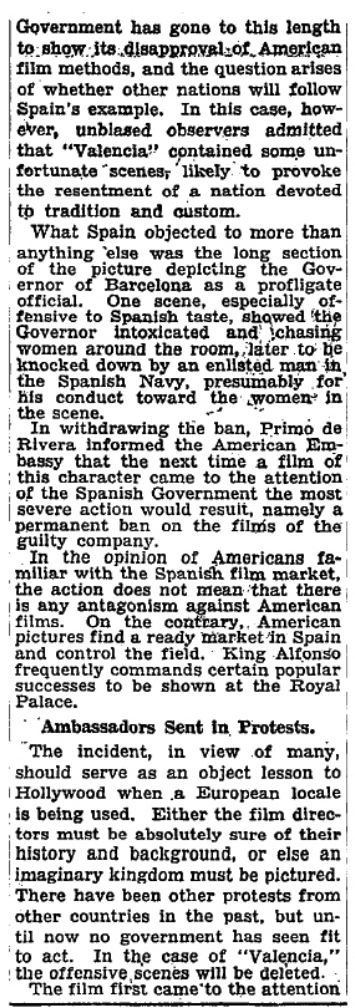

III. Artículo publicado en el New York Times con motivo del levantamiento de la prohibición a la Metro tras la intervención del embajador americano en España. El diario El Sol de Madrid acusaba a los americanos de "miopía intelectual" y de una "vergonzosa falta de cultura".

La estimación final de las pérdidas en contratos de la Metro-Goldwyn Corporation ascendieron a 100.000 pts. de la época, lo que nos puede dar una idea aproximada de la facturación de las compañías americanas en España, ya que la prohibición había durado poco más de un mes. 


\section{Valoración final.}

Como hemos tenido oportunidad de observar a lo largo de estas páginas, la intervención del gobierno norteamericano, a través de su embajada en España, resultó decisiva para la resolución de diferentes conflictos relacionados con la censura española. De no haber sido así, las actividades de la Metro-Goldwyn-Mayer en el mercado español se podrían haber visto seriamente comprometidas durante un largo periodo de tiempo, y las consecuencias económicas hubiesen sido mucho peores para la compañía americana.

La MPPDA, en su intento de controlar todas las situaciones, practicaba un doble discurso: por un lado el institucional (de cara al exterior, que incluía en ocasiones a su propio gobierno) y, por el otro, un discurso interno en el que trataban de dosificar su intrusión en la imagen cinematográfica de determinadas nacionalidades. La carta de Hammond a Hays pone de manifiesto el activo interés que el Departamento de Estado tenía en la clase de representaciones que Hollywood enviaba al exterior. Asimismo, los asuntos relacionados con la censura y la autorregulación pueden aclarar la importancia del mercado extranjero en los negocios de Hollywood de una manera que los estudios puramente económicos no pueden hacer. A finales de los años 20, la MPPDA trataba de controlar de manera más o menos sistemática los continuos problemas de relaciones públicas de la industria cinematográfica dentro y fuera de Estados Unidos.

El grado de reacción de los estudios a las exigencias de la censura extranjera dependía directamente de la importancia económica del mercado en cuestión y del grado en que esas medidas estuvieran apoyadas por acciones diplomáticas. La presión diplomática podía ser tan persuasiva como la fortaleza económica, porque muchos códigos de censura incluían cláusulas que prohibían la exhibición de películas que pudieran ofender a otras naciones.

Mientras las películas fueron mudas, podían ser modificadas de acuerdo a las predilecciones y sensibilidades de las diversas audiencias, tanto nacionales como internacionales, porque estas películas, como apunta de Grazia, se habían revelado bastante maleables a la hora de hacer frente a la censura, pudiéndose introducir alteraciones en varios momentos sin que la película se volviera totalmente incoherente (de Grazia, 2006: 372). Sin embargo, la introducción del sonido redujo significativamente la flexibilidad del medio cinematográfico, y las dificultades a las que se tuvo que enfrentar la industria fueron mayores. Se hizo más necesario que nunca controlar el momento de producción, porque era muy difícil modificar las copias durante la distribución para así atender las demandas de mercados específicos.

En cualquier caso, fueran cuales fueran los mercados, las concesiones de la MPPDA a la representación de los extranjeros en sus películas siempre tuvieron un objetivo muy claro; como Herron le comentó a uno de sus productores: "No es una cuestión... de sensibilidad sobre estos asuntos, sino que es una cuestión de dólares y centavos". 


\section{Referencias bibliográficas.}

BJORK, Ulf Jonas (2000). “The US Commerce Department Aids Hollywood Exports, 1921-1933”. En: Historian 62, n 3 (Spring). p. 575-587.

BORAU, José Luis (dir.) (1998). Diccionario del cine español. Madrid: Alianza y Fundación Autor.

DE GRAZIA, Victoria (2006). El imperio irresistible. Un minucioso análisis del triunfo de la sociedad de consumo estadounidense sobre la civilización europea. Barcelona: Belacqva.

JARVIE, Ian C. (1992). Hollywood's Overseas Campaign. The North Atlantic Movie Trade, 1920-1950. Cambridge: Cambridge University Press.

SEGRAVE, Kerry (1997). American Films Abroad. Hollywood's Domination of the World's Movie Screens from the 1890s to the Present. North Carolina: McFarland \& Co.

THOMPSON, Kristin (1985). Exporting Entertainment. America in the World Film Market 1907-34. London: British Film Institute.

TRUMPBOUR, John (2002). Selling Hollywood to the World. U.S. and European Struggles for Mastery of the Global Film Industry. Cambridge: Cambridge University Press.

ULFF-MØLLER, Jens (2001). Hollywood's Film Wars with France. Film-Trade Diplomacy and the Emergence of the French Film Quota Policy. Rochester: The University of Rochester Press.

VASEY, Ruth (1997). The World According to Hollywood, 1918-1939. Madison: University of Wisconsin Press.

\section{NOTAS}

1 Los documentos consultados pertenecen a los Records of the Department of State regarding internal affairs of Spain, 1910-1929 y Records of the Bureau of Foreign and Domestic Commerce, General Records 1922-1932.

2 Las majors son los grandes estudios de Hollywood que integraban las actividades de producción, distribución y exhibición cinematográfica. En la época de nuestro estudio, tenían esta consideración las siguientes empresas: Paramount Pictures, Loew's Inc. (sociedad matriz de Metro-Goldwyn-Mayer), 20th Century- Fox, Warner Bros. y Radio-Keith-Orpheum (RKO).

3 "Panoramas ingleses. La guerra cinematográfica", Las Provincias, 4-04-1926. Citado en el informe remitido por Clement S. Edwards, cónsul americano en Valencia al Departamento de Estado en Washington el 16-04-1926 bajo el título "Crítica española a las películas americanas".

4 Carta del agregado comercial del la embajada de Estados Unidos en España al Secretario de Estado, 5-05-1926.

5 Ogden H. Hammond fue embajador de Estados Unidos en España desde 1925 hasta 1929.

6 Telegrama de Ogden H. Hammond al Departamento de Estado, 17-10-1927.

7 Carta de Ogden H. Hammond a Frank B. Kellogg, Secretario de Estado, Washington, 25-101927. 
8 Carta de Ogden H. Hammond a Will H. Hays, presidente de la MPPDA, 22-10- 1927.

\section{La autora}

Rocío de la Maya Retamar es Doctora en Comunicación por la Universidad de Málaga y Licenciada en Ciencias de la Imagen por la Universidad Complutense de Madrid. Desde 1994 es profesora del Departamento de Comunicación Audiovisual y Publicidad de la Facultad de Ciencias de la Comunicación de la UMA, desarrollando su labor investigadora en el ámbito de la industria audiovisual, desde la producción de contenidos hasta las nuevas formas de distribución y exhibición digitales. Realizó la tesis doctoral sobre la distribución del cine norteamericano en España durante la etapa muda (1896-1930), ganadora del Premio SGAE de Investigación en el Mercado Cultural y su Entorno al mejor proyecto de Tesis Doctoral. 